\title{
INDONESIA SEBAGAI HOST COUNTRY DALAM EKSPANSI BISNIS MEREK FASHION INTERNASIONAL
}

\author{
Fitri Wahyu Rahmadania \\ Sekolah Tinggi Ilmu Komunikasi Profesi Indonesia \\ Jl. Tegalan No.1 E, Palmeriam, Kec. Matraman, Kota Jakarta Timur \\ Email Korespondensi: rahmadania.fitri@ stikomprosia.ac.id
}

\begin{abstract}
ABSTRAK
Globalisasi dan krisis ekonomi yang terjadi di negara-negara barat menjadi motif utama bagi merek-merek fashion untuk melakukan bisnis ekspansi ke negara penyelenggara khususnya di Asia. Indonesia telah menjadi satu destinasi negara penyelenggara yang menarik bagi beberapa merek fashion yang tidak asing ditelinga seperti H\&M, Pull \& Bear, dan Zara untuk membuka gerai-gerai di beberapa pusat perbelanjaan walaupun memiliki perbedaan yang signifikan baik dari segi budaya, ekonomi, geografis dan kondisi pasar. Faktor budaya, ekonomi, kondisi sosial dan geografis yang berbeda dengan negara asal. Penelitian menjelaskan perlunya pertimbangan mendalam dengan mengacu beberapa elemen seperti 1) jarak dan bentuk geografis; 2) ukuran pasar dan daya beli; 3) tingginya permintaan; 4) franchising sebagai strategi ekspansi; 5) dan adaptasi pada strategi manajemen dan pemasaran merupakan proses evaluasi yang sangat penting dalam proses pemilihan Indonesia sebagai negara penyelenggara dalam bisnis ekspansi. Penelitian ini menggunakan paradigma post-positivistik sebagai dasar untuk teori dengan pendekatan penelitian kualitatif dan metode pengumpulan data melalui wawancara mendalam.
\end{abstract}

Kata Kunci: Ekspansi Bisnis, Merek Fashion Internasional, Franchise

\begin{abstract}
Globalization and economic downturn which occurred in the western countries has driven several fashion brands expand their business to the host countries, spefically in the Asia. Indonesia has became one of host countries destination that attractive for several well-known fashion brands such as $H \& M$, Pull \& Bear, and Zara by opening retail stores in some of shopping mall despite of the significant difference in culture, economic, geographic, and market condition between home and host countries. The research finding showed that detail consideration of several elements in evaluation process of choosing Indonesia as a host country for business expansion such as 1) geographic and physical distance; 2) market size and purchasing power; 3) high demand of fashion industry; 4) franchising as entry strategy; and 5) adapatation in management and marketing strategy. This research based on the post-positivistist paradigm and qualitative research method by collecting the data through in-depth interviews.
\end{abstract}

Keywords: Business Expansion, International Fashion Brand, Franchise 


\section{PENDAHULUAN}

Globalisasi membuat dunia semakin mengecil mendorong beberapa brand ternama melakukan expansi bisnis ke pasar internasional baik antar negara maupun antar benua. Menurut Mishra (2009:38); "With the advent of the 21st century, and the new phenomenon of globalisation, the world markets have become closer and are shrinking in size and getting highly saturated yet volatile."(Kemunculan abad ke-21dan fenomena baru globalisasi, pasar dunia menjadi lebih dekat dan menyusut dalam ukuran dan menjadi sangat jenuh serta tidak stabil). Industri fashion menjadi salah satu industri yang mempunyai produktivitas dan dinamika yang cukup tinggi dan merasakan dampak pasar secara global. Menurut Wingley and Moore (2007), beberapa fashion retails sudah aktif mengoperasikan bisnis mereka baik pada pasar domestik maupun internasional dikarekan efek globalisasi. Fashion yang menjadi lebih global dan preferensi konsumen dunia yang mengikuti tren dunia memberikan kepercayaan diri lebih bagi international brands dalam melakukan ekspansi bisnis ke beberapa negara penyelenggara (host countries). Perkembangan fashion dunia yang cepat berganti merupakan motif utama dari beberapa fashion brands asal negara barat memutuskan untuk melakukan ekspansi ke beberapa negara penyelenggara (host countries).

Ekspansi bisnis bukanlah hal mudah yang dilakukan oleh perusahaan internasional dikarenakan beberapa perbedaan yang menjadi tantangan antara lain budaya, ekonomi, kondisi sosial, dan geografis sehingga perlu ditetapkannya indikator atau elemen yang menjadi bahan evaluasi dalam menganalisa peluang ekspansi bisnis. Dari motif, pemilihan negara penyelenggara hingga strategi manajemen dan pemasaran yang diimplementasikan pada saat melakukan ekspansi bisnis pada dunia fashion merupakan elemen-elemen yang perlu dipertimbangkan sehingga peluang keberhasilan lebih besar (Sakarya et al.,2007; Evans et al., 2008; Loo and Hackley, 2013). Indonesia merupakan salah satu destinasi yang memberikan peluang ekspansi bisnis yang menarik bagi beberapa fashion brands ternama di dunia, dikarenakan pesatnya perubahan infrastuktur, keberagaman budaya, jumlah populasi yang padat, serta meningkatnya kemampuan ekonomi masyarakat merupakan. Sebagaimana artikel online, Global Business Guide Indonesia (2014) mengungkapkan;

"In the largest cities, growing purchasing power, coupled with the young average age of Indonesia's most-courted consumers, should benefit the fashion segment in particular". (Di kota-kota terbesar, meningkatnya kemampuan membeli, ditambah dengan rata-rata umur masyarakat Indonesia yang muda dan mudah dirayu, akan memberikan keuntungan bagi segmen fashion khususnya).

Banyaknya beberapa fashion brands asal negara barat seperti H\&M, Pull \& Bear, dan Zara yang sering dijumpai di beberapa shopping mall di Indonesia membuktikan bahwa Indonesia merupakan salah satu negara penyelenggara (host country) yang memiliki peluang pasar yang besar walaupun memiliki faktor budaya, ekonomi, kondisi sosial dan geografis yang berbeda dengan negara asal (home country). Merek-merek tersebut juga masih bertahan pada pasar fashion Indonesia dengan kompetisi yang cukup ketat dikarenakan tak hanya brand asli Indonesia saja tetapi juga brands asing lainnya yang memiliki keunikan produk yang bervariasi satu sama lainnya. 
Fenomena ini yang mendorong peneliti untuk menganalisa bagaimana international fashion brands mengevaluasi indikator atau elemen yang penting dalam memilih destinasi expansi bisnis di negara-negara penyelenggara khususnya Indonesia yang sampai saat ini masih menjadi salah satu destinasi di Asia Tenggara. Tujuan penelitian ini memberikan pemahaman indikator atau elemen yang dipertimbangkan bagi beberapa merek-merek fashion internasional pada saat melakukan ekspansi bisnis di Indonesia.

\section{Motif Ekspansi Bisnis}

Industri fashion merupakan salah satu bisnis yang tingkat kompetisinya tinggi dan terus berkembang secara pesat sehingga mendorong beberapa brand berskala internasional melakukan ekspansi bisnis ke beberapa negara-negara di seluruh penjuru dunia (host countries). Wingley dan Moore (2007) mengungkapkan bahwa beberapa fashion brands telah aktif beroperasi baik domestik maupun pasar asing melalui ekspansi bisnis lintas negara seiring globalisasi dan tingginya dinamika produk-produk fashion di dunia.

Evans et al. (2008) juga menambahkan bahwa keunikan pasar hingga ukuran pasar asing merupakan faktor yang mendorong brand untuk memasuki pasar di negara penyelenggara. Wingley dan Moore (2007) juga menjelaskan bahwa peluang pasar dalam expansi bisnis internasional terdorong dengan adanya kesamaan preferensi akan produkproduk fashion oleh konsumen dari segala penjuru dunia. Beberapa faktor tersebut menjadi motif utama bagi fashion brand dalam mempertimbangkan motif untuk melakukan ekspansi bisnis di pasar internasional.

\section{Negara Penyelenggara (Host Country)}

Dengan pertimbangan beberapa motif dalam melakukan ekspansi bisnis di pasar internasional, fashion brands harus memilih negara penyelenggara (host countries) yang tepat sebagai destinasi ekspansi bisnis. Dalam pemilihan destinasi diperlukan proses assessment elemen-elemen yang digunakan. Adapun beberapa elemen yang harus dipertimbangkan oleh brand pada saat memilih negara yang tepat sebagai destinasi expansi. Pada umumnya, expansi bisnis skala internasional mempertimbangkan elemen geografi dan budaya sebagai elemen pemilihan destinasi negara penyelenggara bagi fashion brands (Sakarya et al. 2007; dan Doherty 2008).

Etgar dan Rechman-Moore (2010) menjelaskan kebanyakan fashion brands asal negara barat memilih destinasi negara penyelenggara yang memiliki jarak geografis (geographical distance) yang dekat pada awal melakukan ekspansi bisnis berskala internasional. Salah satu contoh, Zara, fashion brand asal Spanyol yang telah aktif melakukan ekspansi bisnis di pasar internasional berawal memilih Portugal dan Paris yang merupakan negara tetangga sebagai destinasi awal dalam ekpansi dikarenakan jarak geografis yang cukup dekat dan akhirnya telah melakukan ekspansi di negara-negara di asia yang memiliki jarak geografis yang sangat jauh (Inditex, 2018). Hal ini menggambarkan proses ekspansi fashion brand secara bertahap yang berdasarkan letak geografis antara negara asal (home country) dengan negara-negara penyelenggara (host countries). Etgar dan Rechman-Moore (2010) juga menjelaskan alasan expansi bisnis berdasarkan jarak geografis yaitu terbatasnya pengetahuan akan pasar di negara 
penyelenggara sehingga fashion brands perlu mempelajari dan mengadopsi pengetahuan baru (local knowledge) yang diperoleh dengan ekspansi pada negara-negara terdekat.

Selain itu, seberapa besar jenjang budaya (cultural distance) antara negara asal dengan negara penyelenggara merupakan salah satu elemen utama pada saat pemilihan destinasi negara penyelenggara. Alexander (1997) menjelaskan brand biasanya memulai melakukan ekspansi bisnis ke negara-negara yang memiliki kesamaan budaya (low cultural distance) untuk beradaptasi setelah sukses brand akan lebih berani melakukan ekpansi ke negara penyelenggara yang memiliki perbedaan budaya yang cukup signifikan (high cultural distance) dengan potensi pasar yang luas. Waarts dan Van Everdingen (2006) menjelaskan alasan brand melakukan ekspansi bisnis ke negara-negara yang memiliki kesamaan budaya pada saat expansi bisnis pertama kali dengan tujuan minimalnya adaptasi yang dilakukan serta dapat mengimplementasikan know-how dan knowledge yang sama dengan negara asal.

\section{METODE PENELITIAN}

Penelitian ini menggunakan paradigma post-positivistik sebagai dasar untuk teori guna membantu dalam mengintepretasikan hasil dari penelitian. Saunders et al. (2009) menjelaskan paradigma post-positivistik merupakan suatu pendekatan penelitian yang mendorong peneliti untuk terjun langsung (direct experience) yang memerlukan pemahaman mendalam dari sumber informasi. Sugiyono (2016) menambahkan bahwa paradigma post-positivistik yang dikenal dengan metode penelitian baru cenderung menggunakan metode penelitian kualitatif dikarenakan proses penelitian yang bersifat kurang terpola. Cresswell (2013) menjelaskan penelitian kualitatif merupakan yang digunakan dalam penelitian yang bersifat eksplorasi atau memahami makna dari individual atau sekelompok individual dari sebuah fenomena sosial. Saunders et al. (2009) menambahkan dalam penelitian kualitatif, peneliti menggunakan pendekatan induktif dalam pengumpulan data yang menggunakan data primer yaitu melalui wawancara mendalam (in-depth interview) dan data sekunder melalui studi pustaka yang berkaitan dengan penelitian. Wilson (2010) menggambarkan pengumpulan data primer merupakan proses penggumpulan data melalui wawancara maupun observasi yang tidak mudah dalam mengolah data sebelum di analisa, sedangkan pengumpulan data sekunder merupakan proses pengumpulan data yang bersumber dari data-data yang telah tersedia seperti laporan tahunan, artikel, jurnal dan lain-lain.

Dari pengumpulan data yang terkumpul, peneliti selanjutnya mengolah data yang diperoleh dari beberapa informan dan menganalisa hasil wawancara dengan mengambarkan serta mengintepretasikan secara mendalam tentang pemahaman maupun temuan-temuan yang saling berkaitan. Saunders et al. (2009) menjelaskan dalam penelitian kualitatif kemampuan peneliti dalam menggambarkan serta mengkaitkan temuan-temuan dari berbagai sumber merupakan hal yang penting sehingga dapat memperkuat keabsahan suatu penelitian. 


\section{HASIL DAN PEMBAHASAN}

Berdasarkan pengumpulan data yang dilakukan, terlihat gambaran sebagaimana yang telah diungkapkan pada kajian pustaka sebelumnya. Beberapa fashion brands asal negara barat telah aktif melakukan ekspansi bisnis ke seluruh penjuru dunia. Perkembangan pesat akan industri fashion dunia menjadi motif utama bagi kebanyakan brands melakukan ekpansi bisnis berskala internasional. Adapun beberapa elemenelemen yang penting bagi brands dalam mempertimbangkan negara penyelenggara (host country) yang sesuai dan tepat sebagai sasaran pasar baru. Dalam penelitian ini, akan dijelaskan secara mendalam dan detil setiap elemen-elemen yang digunakan pada saat pemilihan Indonesia sebagai destinasi expansi bisnis para fashion brands berskala internasional.

\section{Jarak dan Bentuk Geografis}

Seperti pembahasan dalam kajian pustaka fashion brands pada umumnya melakukan ekspansi bisnis ke negara-negara penyelenggara yang memiliki jarak geografis yang dekat dan biasanya memiliki budaya yang hampir sama sehingga adaptasi yang dilakukan cukup sedikit dalam mengimplementasikan sistem manajemen maupun pemasaran. Tetapi seiring globalisasi fashion brands mulai berani melakukan ekspansi ke negara-negara penyelenggaran yang memiliki jarak geografis yang cukup jauh seperti benua Asia hingga Australia. Hal ini terjadi dikarenakan terjadinya economic downturn yang melemahnya pasar fashion di negara barat seperti USA dan Eropa, sehingga menjadi motif bagi brands memutar haluan ke negara-negara dari benua Asia atau lebih dikenal dengan "Second Wave Tigers" seperti Thailand, Malaysia dan Indonesia yang permintaan pasar akan industri fashion cukup besar (Alexander dan Myers 1999; dan Moreau 2008). Economic downturn di negara barat mengakibatkan industri fashion menjadi area bisnis yang sangat sulit dikarenakan ketidakpastian atau penurunan jumlah permintaan, fastchanging season, kompetisi yang semakin ketat sehingga brands mulai melakukan ekspansi bisnis ke negara-negara timur yang menjanjikan.

Seperti temuan pustaka peneliti, yang menunjukan kebanyakan fashion brands berskala internasional melakukan ekspansi berdasarkan jarak dan bentuk geografis dari negara penyelenggara. Fashion brands memutuskan melakukan ekspansi bisnis ke Indonesia setelah berhasil beroperasi di negara-negara tetangga seperti Hongkong, Singapore dan Malaysia yang secara jarak dan bentuk geografis tidak berbeda jauh dibandingkan dengan negara asal brands tersebut. Setelah berhasil beroperasi di pasarpasar tersebut membuat Indonesia menjadi salah satu destinasi yang tepat (eligible) menjadi negara penyelenggara bagi produk fashion ternama dunia.

Adapun alasan melakukan ekspansi di Indonesia setelah Hongkong, Singapore dan Malaysia yaitu jarak geografis negara tersebut lebih dekat dibandingkan di Indonesia serta sebagai media bagi brands untuk mempelajari pengetahuan lokal (local knowledge) akan budaya negara-negara di Asia yang cukup signifikan perbedaannya dengan negara asal barat. Berdasarkan pengetahuan ini yang akan membantu brands dalam memutuskan strategi ekspansi bisnis apa yang tepat digunakan mulai dari strategi model expansi (entry mode strategy), strategi manajemen (management strategy) hingga strategi pemasaran (marketing strategy) yang akan diimplementasikan di Indonesia. Sehingga brands dapat merencanakan adaptasi apa saja yang diperlukan dan berbeda dengan negara asal (home country) agar dapat bertahan dan sukses pada kompetisi pasar fashion Indonesia. 


\section{Ukuran Pasar dan Daya Beli}

Elemen yang cukup penting dalam pemilihan destinasi ekspansi bisnis yaitu ukuran dari pasar (market size) dari suata negara penyelenggara. Indonesia menjadi destinasi menarik bagi kebanyakan fashion brands asal negara asing dikarenakan jumlah populasi yang banyak sehingga ukuran sasaran pasar yang cukup luas. Indonesia yang memiliki estimasi populasi sejumlah 262.787 .403 penduduk membuat menjadi peringkat ke empat di dunia (The World Factbook, 2018). Populasi yang padat membuat potensi sasaran pasar baru yang besar bagi kebanyakan fashion brands untuk melakukan ekspansi dengan membuka gerai-gerai di beberapa pusat belanja Indonesia.

Selain itu kondisi ekonomi merupakan elemen penting yang dapat memproyeksikan suatu negara penyelenggara sebagai destinasi ekspansi bisnis yang potensial bagi international fashion brands. Artikel ATKearney (2014) menjelaskan bahwa Indonesia merupakan salah satu pasar yang menguntungkan walaupun adanya hambatan tetap saja industri retail bertahan kuat dalam jangka waktu panjang seiring dengan perkembangan populasi, urbanisasi, generasi muda yang memiliki tingkat edukasi dan pendapat yang lebih baik, serta perkembangan infrastruktur yang berkelanjutan dan berkesinambungan. Selain itu masyarakat Indonesia khususnya generasi muda telah mengikuti tren fashion terkini melalui berbagai sumber sepeti majalah, media sosial dan review dari fashion bloggers/influencers yang menjamur di era 4.0 ini. Faktor-faktor ini yang membuat tingginya daya beli (purchasing power) di kalangan generasi muda di Indonesia sehingga potensi penjualan akan produk-produk fashion brands asing cukup diminati.

\section{Tingginya Permintaan}

Indonesia merupakan salah satu negara yang memiliki konsumen yang besar dan aktif mengikuti tren fashion terkini yang sudah mengenal berbagai brands ternama di dunia. Hal ini dikarenakan penyebaran informasi yang luas dan cepat dengan bantuan media massa seperti majalah, media sosial dan electronic word-of-mouths (eWOM) dari beberapa pakar atau tokoh di industri fashion. Populasi dengan kelas sosial menengah yang semakin banyak di Indonesia, sehingga banyak yang telah melihat produk berdasarkan kualitas dan image khususnya beberapa brands asal negara asing.

Mayoritas konsumen di Indonesia menyukai merek-merek internasional yang ternama yang menawarkan harga yang sesuai dengan kualitas yang terjamin serta up-todate mengikuti tren fashion terkini. Selain dari media massa, konsumen di Indonesia mengetahui akan produk-produk dari fashion brands dikarenakan pengalaman membeli pada saat mereka bepergian ke luar negeri dimana telah tersedia gerai-gerai brands tersebut. Dikutip dari artikel online McKinsey Insight (2013);

"Indonesians attach more importance to brands than do the customers of any nation we've seen at this stage of development" (Orang Indonesia lebih mementingkan merek dibandingkan konsumen dari negara lain di fase perkembangan saat ini).

Selain itu dikutip dari Business Monitor Internasional (2014), keberadaan brands asing yang masih terbatas memotivasi beberapa fashion retailers untuk memasuki pasar Indonesia dengan harapan menarik perhatian generasi muda yang haus akan produk fashion asing dan populasi yang terus berkembang pesat. Hal ini terlihat pada saat event pra-pembukaan salah satu fashion brand asal Swedia yang membuka gerai pertamanya di 
Indonesia pada tahun 2013 yang dihadiri sebanyak 4.000 undangan mengalahkan pembukaan gerai brand ini di Thailand (Indra, 2013). Indonesia menjadi salah satu destinasi ekspansi bisnis yang sangat menarik dikarenakan tingginya jumlah permintaan konsumen yang meminati industri fashion khususnya generasi muda yang selalu mengikuti tren dan berpotensi sebagai konsumen dalam jangka panjang dikarenakan industri ini tergolong fast changing.

\section{Franchising sebagai Strategi Ekspansi}

Fashion brands juga mempertimbangkan strategi apa yang digunakan untuk melakukan ekspansi bisnis ke pasar di negara penyelenggara dikarenakan regulasi dari masing-masing negara berkaitan dengan investor asing berbeda satu dengan lainnya sehingga perlu memilih cara yang tepat. Pada umumnya, brands lebih memilih untuk mengoperasikan gerai sendiri tanpa adanya campur tangan pihak tertentu seperti joint ventures atau franchise. Hanya saja beberapa negara penyelenggara mempunyai aturan untuk perusahaan asing perlu berkolaborasi dengan pengusaha lokal agar dapat beroperasi di negara tersebut. Hal ini yang diberlakukan oleh pemerintah Indonesia, yang tidak memudahkan perusahaan asing untuk masuk dan beroperasi di pasar fashion Indonesia.

Menurut artikel Global Business Guide (2012), pemerintah telah menetapkan beberapa regulasi yang harus dipenuhi oleh franchisors asing sebelum memasuki pasar Indonesia dengan tujuan melindungi pengusaha lokal pada industri tersebut. Indonesia yang memiliki jarak yang jauh dengan negara asal brand dan resiko ekonomi serta politik yang cukup tinggi. Faktor-faktor tersebut yang membuat beberapa fashion brands mengunakan metode franchise untuk memasuki industri fashion di Indonesia tidak hanya regulasi tetapi juga untuk meminimalisasi resiko dalam ekspansi bisnis betujuan untuk keberlangsungan brand jangka panjang.

\section{Adaptasi Strategi Manajemen dan Pemasaran}

Strategi manajemen dan pemasaran dari fashion brands di Indonesia mengikuti sistem yang diimplementasikan pada negara asal dikarenakan menggunakan franchise sebagai metode ekspansi sehingga telah menetapkan acuan yang digunakan oleh geraigerai di Indonesia guna mempertahankan visi, misi, dan image dari brands tersebut. Hanya saja untuk kelola manajemen dan pemasaran di Indonesia telah mengadaptasi dengan sistem yang berlaku di pasar fashion Indonesia. Beberapa brands memperbolehkan adaptasi yang telah diajukan oleh perusahaan di Indonesia pada saat proses awal franchise.

Salah satu adaptasi yang diperbolehkan yaitu berkaitan dengan rekrutmen staff untuk operasional brands tersebut. Perusahan lokal diberikan wewenang dalam sistem rekrutemen sumber daya manusia hanya saja brand telah menetapkan guidelines tentang kualifikasi dan kompetensi yang harus sesuai dengan standar brands. Brands juga sering mempekerjakan staff lokal yang memiliki kompetensi dalam berbahasa Inggris atau lulusan dari perguruang tinggi di luar negeri dengan alasan untuk mempermudah komunikasi antara manajemen baik di negara asal maupu negara penyelenggara.

Selain itu, regulasi pemerintah Indonesia yang membatasi jumlah pekerja asing (expatriates) pada perusahaan asing yang beroperasi di Indonesia memaksa beberapa fashion brands untuk mempekerjakan penduduk asli pada sistem manajemen yang mengoperasikan bisnis ekspansi. 
Tidak hanya manajemen saja, strategi pemasaran di Indonesia juga telah diadaptasikan sedikit dengan kondisi pasar fashion sehingga brands dapat bersaing dan bertahan dalam kompetisi. Salah satu strategi pemasaran yang berbeda dengan negara asal yaitu dengan pemberlakuan membership bagi konsumen dari beberapa brands yang bertujuan tidak hanya untuk penjualan produk saja tetapi juga untuk membangun hubungan jangka panjang dengan konsumen (customer relationship). Selain itu, beberapa fashion brands asing ikut berpartsipasi mengadopsi budaya maupun ritual yang biasa dilakukan oleh konsumen di Indonesia dengan menyelenggarakan kegiatan sale pada periode-periode festival yang di negara asal tidak ada contohnya Idul Fitri dan Imlek yang kuat dengan nuansa agama dan budaya.

Dengan adaptasi yang dilakukan baik strategi manajemen maupun pemasaran yang dilakukan oleh brands, merupakan elemen utama yang dijadikan pertimbangan pada saat ekspansi bisnis bertujuan untuk mampu bertahan dan mencapai sasaran pasar fashion di Indonesia. Apabila brands tetap memaksakan sistem manajemen dan pemasaran yang seutuhnya sama dengan negara asal, resiko gagal akan lebih besar dan kemungkinan untuk bertahan di pasar fashion di Indonesia sangat kecil.

\section{KESIMPULAN DAN SARAN}

Penelitian ini bertujuan untuk memami indikator atau elemen apa saja yang dipertimbangkan oleh fashion brands berskala internasional untuk memilih Indonesia sebagai destinasi ekspansi bisnis. Dari hasil pembahasan terlihat adanya beberapa elemen penting selain motif utama dari ekspansi bisnis yang digunakan sebagai bahan evaluasi yang membuat Indonesia sebagai destinasi ekspansi bisnis yang berpotensi khususnya di industri fashion. 1) Jarak dan Bentuk Geografis; 2) Ukuran Pasar dan Daya Beli; 3) Tingginya Permintaan; 4) Franchising sebagai Strategi Ekspansi; dan 5) Adaptasi Strategi Manajemen dan Pemasaran merupakan elemen-elemen yang digunakan oleh beberapa fashion brands asal USA dan Eropa pada saat pemilihan Indonesia sebagai potential host country dalam ekspansi bisnis. Jarak dan bentuk geografis Indonesia mempermudah fashion brands dalam melakukan ekspansi bisnis berkelanjutan di negaranegara penyelenggaran yang terletak pada satu wilayah. Ukuran pasar dan daya beli konsumen di Indonesia juga merupakan elemen penting dikarenakan ukuran pasar dan kemampuan beli yang besar mengindikasikan potensi penjualan yang besar dan berkelanjutan.

Tingginya permintaan industri fashion di kalangan generasi muda di Indonesia yang merupakan sasaran pasar utama juga menjadi elemen yang memberanikan brands untuk melakukan ekspansi walaupun secara stabilitas memiliki resiko tinggi. Pilihan dengan franchising sebagai strategi ekspansi juga mempermudah brands untuk meminimalisasi resiko dan mematuhi regulasi pemerintah Indonesia yang membatasi kebebasan bagi perusahaan asing yang beroperasi di Indonesia.

Elemen terakhir yang menjadi pertimbangan yaitu sedikitnya adaptasi dengan regulasi, budaya serta kepercayaan yang berlaku di Indonesia merupakan proses yang telah dilakukan pada strategi manajemen dan pemasaran yang diimplementasikan di Indonesia sehingga mempermudah brands untuk tetap bertahan di pasar fashion Indonesia tanpa harus mengubah visi, misi, dan image yang telah dibangun pada negara asal. 
Dari penelitian yang terbatas ini, telah teridentifikasi secara jelas elemen-elemen yang menjadi pertimbangan bagi beberapa fashion brands berskala internasional yang memilih Indonesia sebagai destinasi ekspansi bisnis. Dengan penelitian ini diharapkan, adanya temuan-temuan baru yang menjadi elemen tambahan yang digunakan oleh fashion brands khususnya pada saat setelah pemilihan destinasi ekspansi bisnis hingga strategi untuk dapat bertahan dan sukses di pasar Indonesia seiring dengan perubahan yang terus terjadi baik skala lokal maupun skala global.

\section{UCAPAN TERIMA KASIH}

Dengan selesainya jurnal ini, peneliti mengucapkan terima kasih kepada seluruh pihak yang telah membantu dalam proses penelitian, diantaranya Sekolah Tinggi Ilmu Komunikasi Profesi Indonesia (STIKOM PROSIA) sebagai institusi yang membantu dalam tahap penyelesaian, beberapa narasumber yang bersedia meluangkan waktu untuk memberikan informasi berkaitan dengan penelitian serta pihak-pihak lain yang tidak bisa disebutkan.

Peneliti berharap dengan terbitnya jurnal ini dapat membantu peneliti selanjutnya untuk meneliti lebih mendalam khususnya berkaitan dengan international fashion brands di pasar Indonesia. Akhir kata, turut mengucapkan terima kasih kepada Universitas Sahid yang telah berkenan menerbitkan jurnal yang berjudul "Indonesia Sebagai Host Country Dalam Ekspansi Bisnis Merek Fashion Internasional

\section{DAFTAR PUSTAKA}

Alexander, N., \& Myers, H. (1999). European retail expansion in South East Asia. European Business Review, 99(2), 91-104.

Alexander, N., \& Doherty, A. M. (2009). International retailing. Oxford university press. Business Monitor International, (2014). Retail. [Online] Tersedia di: http://www.businessmonitor.com [Diakses pada tanggal 21 Desember 2018].

Creswell, J. W. (2010). Research design pendekatan kualitatif, kuantitatif, dan mixed. Yogyakarta: Pustaka Pelajar.

Doherty, A. M. (2009). Market and partner selection processes in international retail franchising. Journal of Business Research, 62(5), 528-534..

Etgar, M., \& Rachman-Moore, D. (2010). Geographical expansion by international retailers: A study of proximate markets and global expansion strategies. Journal of Global Marketing, 23(1), 5-15.

Evans, J., Bridson, K., Byrom, J., \& Medway, D. (2008). Revisiting retail internationalisation: Drivers, impediments and business strategy. International Journal of Retail \& Distribution Management, 36(4), 260-280.

Global Business Guide Indonesia, (2012). Franchise law in Indoenesia. [Online] Tersedia di:

http://www.gbgindonesia.com/en/main/business_guide/franchise_law_in_indone sia.php [Diakses pada tanggal 15 Desember 2018].

Global Business Guide Indonesia, (2014). Indonesia's retail boom is far from over. [Online]

Tersedia

di: 
http://www.gbgindonesia.com/en/services/article/2014/indonesia_s_retail_boom _is_far_from_over.php [Diakses pada tanggal 15 Desember 2018].

Kearney, A. T. (2014). Full Steam Ahead for Global Retailers. Retreived May, 26, 2015.

Kompas.com, (2013). Pra-Pembukaan Toko H\&M Jakarta Jadi Yang Terheboh. [Online] Tersedia di: https://lifestyle.kompas.com/read/2013/10/04/1905033/PraPembukaan.Toko.H.M.Jakarta.Jadi.yang.Terheboh?page=all [Diakses pada tanggal 25 Januari 2019].

Kuang-Ying Loo, B., \& Hackley, C. (2013). Internationalisation strategy of iconic Malaysian high fashion brands. Qualitative Market Research: An International Journal, 16(4), 406-420.

McKinsey Insights \& Publications, (2013). Understanding the diversity of Indonesia's consumers. [Online] Tersedia di: http://www.mckinsey.com/insights/asiapacific/understanding_the_diversity_of_indonesias_consumers [Diakses pada tanggal 15 September 2018].

Mishra, A. (2009). STRATEGIC BRAND MANAGEMENT OF INTERNATIONAL FASHION RETAILERS IN SOUTH ASIA. Pranjana: The Journal of Management Awareness, 12(2).

Moreau, R. (2008). H\&M and Inditex's Global Expansion Strategies. Euromonitor International. pp. 38-41.

Sakarya, S., Eckman, M., \& Hyllegard, K. H. (2007). Market selection for international expansion: Assessing opportunities in emerging markets. International Marketing Review, 24(2), 208-238.

Saunders, M. N. (2011). Research methods for business students, 5/e. Pearson Education India.

Sugiono, M. P. K., \& Kuantitatif, P. (2007). kualitatif dan R\&D. Bandung: Alfabeta.

The World Factbook, (2018). Indonesia. [Online] Tersedia di: https://www.cia.gov/library/publications/the-world-factbook/geos/id.html [Diakses pada tanggal 14 Februari 2019].

Waarts, E., \& van Everdingen, Y. M. (2006). Fashion retailers rolling out across multicultural Europe. International Journal of Retail \& Distribution Management, 34(8), 645-657.

Wigley, S., \& Moore, C. M. (2007). The operationalisation of international fashion retailer success. Journal of Fashion Marketing and Management: An International Journal, 11(2), 281-296.

Wilson, J. (2014). Essentials of business research: A guide to doing your research project. Sage. 